\title{
Utilização da vacina Escherichia coli J5 na imunização de vacas leiteiras contra mastites causadas por $E$. coli $^{1}$
}

\author{
Lívio R. Molina ${ }^{2 *}$, Mariana B. Gentilini², Antônio U. Carvalho ${ }^{2}$, Elias J. Facury Filho², \\ Gustavo H.F.A. Moreira² ${ }^{2}$ Luiz Paulo V. Moreira $^{3}$ e Reuel L. Gonçalves ${ }^{3}$
}

\begin{abstract}
Molina L.R., Gentilini M.B., Carvalho A.U., Facury Filho E.J., Moreira G.H.F.A., Moreira L.P.V. \& Gonçalves R.L. 2013. [Use of an Escherichia coli J5 vaccine on immunization of dairy cows against mastitis caused by $\boldsymbol{E}$. coli.] Utilização da vacina Escherichia coli J5 na imunização de vacas leiteiras contra mastites causadas por E. coli. Pesquisa Veterinária Brasileira 33(3):291-298. Departamento de Clínica e Cirurgia Veterinárias, Escola de Veterinária, Universidade Federal de Minas Gerais, Av. Antonio Carlos 6627, Cx. Postal 567, Campus Pampulha, Belo Horizonte, MG 30123-970, Brazil. E-mail: lmolina@vet.ufmg.br

We evaluated the use of Escherichia coli J5 vaccine immunization in dairy cows for the prevention and control of mastitis caused by E. coli. Were analyzed the prevalence of postpartum intramammary infections (IMM), occurrence and severity of clinical cases of mastitis in the first 100 days of lactation, influence on somatic cell count (SCC) and milk production. The experimental group consisted of 187 animals that were divided into two groups, vaccinated and unvaccinated cows. Immunizations occurred 60 days before calving, 30 days before calving and the first week postpartum. On the day of drying and seven days after birth, samples were collected for microbiological diagnosis of mastitis pathogens. The occurrence of clinical cases was verified by testing during the milking and data was recorded related to the intensity and duration. Samples were collected monthly starting at day ten of lactation to evaluate the CCS. Milk production was recorded monthly for the first 100 days of lactation. It was found in the vaccinated group reduction in the prevalence of $E$. coli in the postpartum period, the occurrence of clinical cases of $E$. coli in the first 100 days of lactation as well the intensity of these clinical cases. There were no statistically significant differences in CCS, however vaccinated cows had higher milk production, compared to unvaccinated cows. Vaccination with E. coli J5 was effective in reducing the prevalence of intramammary infections (IMM) at calving, occurrence and intensity of clinical cases and an increase in milk production in the first 100 days of lactation.

INDEX TERMS: Dairy cattle, vaccine, mastitis, Escherichia coli J5, coliform.
\end{abstract}

RESUMO.- Avaliou-se a utilização da vacina Escherichia coli J5, na imunização de vacas leiteiras, para prevenção e controle da mastite causada por E. coli através da análise da prevalência das infecções intramamárias (IMM) no pós-parto, ocorrência e intensidade dos casos clínicos de mastite nos primeiros 100 dias de lactação, influência na

\footnotetext{
${ }^{1}$ Recebido em 17 de outubro de 2012.

Aceito para publicação em 23 de novembro de 2012.

${ }^{2}$ Departamento de Clínica e Cirurgia Veterinárias, Escola de Veterinária, Universidade Federal de Minas Gerais (UFMG), Av. Antonio Carlos 6627, Cx. Postal 567, Campus Pampulha, Belo Horizonte, MG 30123-970, Brasil. *Autor para correspondência: lmolina@vet.ufmg.br

${ }^{3}$ Biogénesis Bagó, Av. Manoel Ribas 985, 5a andar, Mercês, Curitiba, PR 80810-000, Brasil.
}

contagem de células somáticas (CCS) e produção de leite. 0 grupo experimental foi composto de 187 animais, divididos em 2 grupos, vacas vacinadas e não vacinadas. As imunizações ocorreram 60 dias antes do parto, 30 dias antes do parto e na primeira semana pós-parto. No dia da secagem e sete dias após o parto foram coletadas amostras para diagnóstico microbiológico dos patógenos causadores de mastite. A ocorrência de casos clínicos foi verificada pelo teste da caneca durante as ordenhas sendo registrados os dados relacionados à intensidade. Amostras foram coletadas mensalmente, a partir do décimo dia de lactação, para avaliação da CCS. A produção de leite foi registrada mensalmente nos primeiros 100 dias de lactação. Verificou-se no grupo vacinado, redução na prevalência de E. coli no 
pós-parto, na ocorrência de casos clínicos por E.coli nos primeiros 100 dias de lactação bem como na intensidade destes casos clínicos. Não foram observadas diferenças estatísticas significativas na CCS, entretanto vacas vacinadas apresentaram maior produção de leite, comparadas às vacas não vacinadas. A vacinação com $E$. coli J5 foi eficaz em reduzir a prevalência de infecções intramamárias (IMM) ao parto, ocorrência e intensidade dos casos clínicos e aumento na produção de leite nos primeiros 100 dias de lactação.

TERMOS DE INDEXAÇÃO: Gado de leite, vacina, mastite, Escherichia coli J5, coliforme.

\section{INTRODUÇÃO}

As bactérias conhecidas como coliformes compreendem o grupo mais importante de microrganismos responsáveis pelos casos de mastite clínica ambiental. 0 maior impacto econômico das mastites por coliformes baseia-se no custo decorrente dos casos clínicos de mastite aguda, devido ao grande descarte de leite, à ineficiência do tratamento com antibióticos e à alta taxa de mortalidade relacionada ao choque endotóxico oriundo da infecção por estes agentes.

A ocorrência de novas infecções intramamárias (imm) no período seco é um dos principais fatores que afetam a manifestação de mastite clínica por coliformes no início da lactação, sendo estes casos mais severos e associados ao período de imunossupressão. Observa-se que, em algumas circunstâncias, as concentrações de anticorpos no soro e no leite podem aumentar com o uso de vacinas, contra coliformes, constituídas de microorganismos mutantes, tais como E. coli J5. A vacinação, portanto, pode ser eficaz no aumento da resistência das vacas às infecções por coliformes no período pós-parto, reduzindo, significativamente, as perdas causadas por esta doença.

Estudos controlados, na Europa e Estados Unidos, demonstraram a eficiência da imunização de animais com $E$. coli J5, não somente no que se refere à ocorrência de novas infecções intramamárias e de casos clínicos de mastite, bem como a intensidade dos mesmos. No entanto, verifica-se que as condições de produção e, consequentemente os fatores de risco, em rebanhos brasileiros são bastante distintas, se comparadas a outros países. Neste contexto, este estudo teve como objetivo avaliar a eficácia da utilização de uma vacina comercial, contendo a bacterina Escherichia coli J5, na prevenção e controle das mastites clínicas causadas por coliformes, em especial Escherichia coli, em diferentes ordens de lactação. Para tanto, foi analisada a prevalência das infecções intramamárias por estes agentes no pós-parto, a ocorrência e intensidade dos casos clínicos de mastite nos primeiros 100 dias de lactação, bem como sua influência na contagem de células somáticas e produção de leite em vacas e novilhas leiteiras.

\section{MATERIAL E MÉTODOS}

O estudo foi realizado entre março e julho de 2007, em um rebanho comercial no município de Pitangui, MG, composto de 450 vacas mestiças Holandês x Gir leiteiro, em lactação, com produção média de $25 \mathrm{~kg}$ de leite/dia. Os animais foram ordenhados duas vezes ao dia em um intervalo de 12 horas, em equipamento me- cânico tipo espinha de peixe com 24 conjuntos $(2 \times 12=24)$ e mecanismo de extração automática de teteiras. A fazenda adota um programa intensivo de controle de mastite por meio dos seguintes procedimentos: rotina de ordenha higiênica, utilização de terapia de vacas secas, manutenção da limpeza dos ambientes de permanência dos animais, adequada limpeza e manutenção do equipamento de ordenha e tratamento imediato de todos os casos clínicos de mastite. Há, também, o controle intensivo de patógenos contagiosos - Staphylococcus aureus e Streptococcus agalactiae - de baixa prevalência na fazenda. Os animais infectados com esses patógenos, identificados por meio de culturas microbiológicas realizadas após o parto, eram descartados do rebanho. Resultados de cultura microbiológica do tanque de refrigeração e culturas individuais realizados antes do início do estudo demonstravam que as infecções intramamárias eram causadas predominantemente por patógenos ambientais.

O grupo experimental possuía 187 animais distribuídos ao acaso, obedecendo à ordem de parto, produção de leite, média de contagem de células somáticas da última lactação e provável data de parto, em dois grupos experimentais: J5V (n=96) - grupo de vacas vacinadas que receberam 3 doses de vacina contra Escherichia coli (Rotatec®- J5); J5Vcont $(\mathrm{n}=91)$ ) grupo de vacas controle que não receberam nenhuma dose da vacina contra Escherichia coli (Rotatec $\AA$ - J5).

Os animais foram imunizados com a vacina comercial (Rotatec®- J5 Biogénesis-Bago, Paraná, Brasil) obedecendo ao seguinte protocolo: Grupo J5V - três aplicações por via subcutânea na dose de $3 \mathrm{~mL}$, aplicadas com seringa dosadora no terço médio do pescoço - duas doses da vacina foram administradas no pré-parto, a primeira 60 dias antes do parto previsto e a segunda 30 dias após a primeira e uma terceira dose administrada na primeira semana após o parto. Todos os animais foram mantidos sob as mesmas condições quanto às instalações, nutrição e ambiente, durante o período experimental.

0 tratamento com antibiótico específico para vacas secas, à base de cloxacilina benzatina, foi realizado em todas as vacas, 60 dias antes do parto previsto, isto é, no dia da secagem. Para realização do mesmo, após a ordenha e esgota completa das vacas, utilizou-se desinfecção e antissepsia dos tetos com hipoclorito de sódio (pré-dipping); secagem dos tetos com papel toalha após 30 segundos; antissepsia do esfíncter do teto com algodão embebido em álcool 70\% e infusão do medicamento, utilizando-se seringa de cânula curta. Após a aplicação do medicamento, foi realizada nova antissepsia com iodo (pós-dipping). As vacas que apresentaram período seco maior que 60 dias ou as que abortaram durante o período experimental foram excluídas do estudo.

No momento da secagem, sete dias após o parto e quando detectados casos clínicos de mastite colheram-se amostras de leite para diagnóstico microbiológico individual visando à identificação de patógenos causadores de mastite. As amostras de leite foram obtidas imediatamente antes da ordenha, após descarte dos três primeiros jatos de leite, desinfecção dos tetos com solução de hipoclorito de sódio e secagem com papel toalha descartável. No momento da coleta, realizou-se antissepsia do esfíncter do teto utilizando algodão umedecido em álcool a 70\%. Os jatos dos quatro tetos forneciam uma amostra única, composta e acondicionada em frascos estéreis previamente identificados. 0 material amostrado foi congelado e encaminhado em recipiente isotérmico ao laboratório para isolamento e caracterização dos microrganismos. Volumes de $10 \mathrm{ml}$ de cada amostra foram semeados com alça calibrada e descartável em cada quadrante de uma placa de ágar-sangue contendo $5 \%$ de sangue desfibrinado de carneiro, seguindo-se incubação a $35^{\circ} \mathrm{C}$, por 24 horas, de acordo com as recomendações de Harmon et al. (1990). 
Após o período de incubação, realizou-se a primeira leitura das placas, observando-se o crescimento microbiano, aspecto, coloração e o número de colônias presentes. Em seguida, as placas foram incubadas a $35^{\circ} \mathrm{C}$ por mais 24 horas, realizando-se a segunda leitura após 48 horas de incubação. Nas amostras de leite que apresentaram crescimento de microrganismos, selecionou-se uma colônia representativa, a qual foi semeada em ágar BHI (Brain Heart Infusion - ágar infusão de cérebro e coração) e incubada a $35^{\circ} \mathrm{C}$ por 24 horas. Após este período, os isolados foram examinados ao microscópio em esfregaços corados pela técnica de Gram e avaliados quanto à produção de catalase para, então, serem submetidos aos testes de identificação (Brito \& Brito 1999).

Amostras de leite compostas e individuais, destinadas à contagem de células somáticas (CCS), foram coletadas mensalmente a partir do $10^{\circ}$ dia de lactação, segundo o protocolo do National Mastitis Council (NMC 1999). Estas foram retiradas diretamente de medidores de leite acoplados ao equipamento de ordenha e acondicionadas em frascos contendo dois comprimidos do conservante Bronopol (2-bromo-2-nitropropano-1,3-diol), permitindo sua conservação à temperatura ambiente. As amostras foram homogeneizadas por inversão do frasco, até a completa dissolução dos comprimidos, e enviadas ao laboratório. As análises de CCS foram realizadas pelo método eletrônico (equipamento Bentley CombSystem ${ }^{\circledR} 2300$ ).

O monitoramento da ocorrência de mastite subclínica foi feito por meio de acompanhamento individual. Considerou-se portador de mastite subclínica o animal que apresentasse CCS $>250.000$ células/mL, de acordo com Green et al. (2002).

A ocorrência de mastite clínica foi determinada pelo teste da caneca telada, executado pelos funcionários responsáveis pela ordenha. Os casos clínicos de mastite foram classificados, de acordo com sua intensidade, em grau 1 - apenas alterações visíveis no leite, isto é, coágulos; grau 2 - presença de coágulos e inflamação no úbere; e grau 3 - coágulos, inflamação no úbere e acometimento sistêmico (Bradley \& Green 2001). Foram consideradas a duração e a intensidade de casos clínicos durante o período experimental com o objetivo de comparar os grupos vacinados e não vacinados.

A produção de leite foi avaliada, mesalmente, a partir do $10^{\circ}$ dia de lactação entre os meses de março a junho. A produção foi mensurada por meio de medidores de leite acoplados ao equipamento de ordenha, nas ordenhas da manhã e da tarde, possibilitando, assim, a avaliação da produção individual e diária dos animais.

Para as análises dos dados relacionados à produção, CCS e composição do leite, utilizou-se o delineamento inteiramente ao acaso, em sistema de parcelas subdivididas para 15 tratamentos em arranjo fatorial $5 \times 3$ - cinco grupos e três períodos de coleta
- com os grupos na parcela e períodos de coleta na subparcela. Usou-se o teste SNK para comparação de médias, utilizando-se os recursos do programa SAS (SAS 1999), a 5\% de probabilidade. Os dados de CCS foram transformados em $\log _{10}$ CCS para que adquirissem distribuição normal. A frequência de microrganismos no pós-parto e a ocorrência de casos clínicos durante a lactação, bem como os dados relacionados à intensidade dos casos clínicos, foram analisados empregando-se quadros de contigência e teste exato de Fisher. Para interação de fatores usou-se o teste de McNemar, e a análise da intensidade dos casos clínicos utilizou-se somente a análise descritiva dos dados.

\section{RESULTADOS E DISCUSSÃO}

No Quadro 1 apresenta-se a prevalência de infecções intramamárias (IMM), na secagem e pós-parto, em vacas vacinadas e não vacinadas. Houve redução $(\mathrm{p}<0,05)$ na prevalência de Escherichia coli no pós-parto, no grupo de vacas vacinadas (J5V), comparadas às não vacinadas (J5Vcont). Não houve diferença significativa entre os grupos com relação aos outros patógenos ( $p>0,05)$. Atribui-se este resultado ao efeito do tratamento com antibiótico realizado no dia da secagem, isto é, à terapia de vacas secas e à ocorrência de cura espontânea, principalmente relacionada aos coliformes, geralmente presente durante o período seco. Este resultado evidencia a importância desta terapia na resolução de infecções pré-existentes e prevenção de novas infecções durante o período seco, especialmente, aquelas causadas por outros agentes que não os coliformes. Em ambos os grupos, quando observados isoladamente, nota-se redução significativa $(\mathrm{p}<0,05)$ na porcentagem de animais infectados no pós-parto, com aumento na porcentagem de animais com resultados negativos na cultura microbiológica (Quadro 1). Apesar de não terem sido percebidas diferenças estatísticas significativas, entre os grupos, notou-se um aumento de $100 \%$ nos animais negativos na cultura microbiológica em vacas vacinadas (J5V), sendo este aumento de $50 \%$ em animais não vacinados (J5Vcont). Todas as vacas receberam antibiótico específico para vacas secas no dia da secagem, isto é, 60 dias antes do parto. No entanto, constata-se a ocorrência de melhores resultados, considerando-se o aumento em animais negativos, no grupo de vacas vacinadas (J5V). Este fato indica alguma contribuição da imunização com E.coli J5 na eliminação de infecções adquiridas durante o período seco, em especial as causadas

Quadro 1. Prevalência de infecções intramamárias em vacas vacinadas e não vacinadas, na secagem e pós-parto, segundo os tratamentos

\begin{tabular}{|c|c|c|c|c|c|c|c|c|c|c|c|c|}
\hline \multirow[t]{4}{*}{ Grupos } & \multicolumn{12}{|c|}{ Microrganismo } \\
\hline & \multicolumn{4}{|c|}{ E.coli } & \multicolumn{4}{|c|}{ Negativo } & \multicolumn{4}{|c|}{ Outros* } \\
\hline & \multicolumn{2}{|c|}{ SEC $^{1}$} & \multicolumn{2}{|c|}{$\mathrm{POS}^{2}$} & \multicolumn{2}{|c|}{$\mathrm{SEC}^{1}$} & \multicolumn{2}{|c|}{$\mathrm{POS}^{2}$} & \multicolumn{2}{|c|}{$\mathrm{SEC}^{1}$} & \multicolumn{2}{|c|}{$\mathrm{POS}^{2}$} \\
\hline & $\%$ & $\mathrm{n}$ & $\%$ & $\mathrm{n}$ & $\%$ & $\mathrm{n}$ & $\%$ & $\mathrm{n}$ & $\%$ & $\mathrm{n}$ & $\%$ & $\mathrm{n}$ \\
\hline $\mathrm{J} 5 \mathrm{~V}(\mathrm{n}=96)$ & 8,33 & $8^{A}$ & 1,04 & $1^{\mathrm{aB}}$ & 37,50 & $36^{\mathrm{A}}$ & 73,96 & $71^{\mathrm{B}}$ & 54,17 & $52^{\mathrm{A}}$ & 25,00 & $24^{\mathrm{B}}$ \\
\hline J5Vcont $(n=91)$ & 10,98 & $10^{\mathrm{A}}$ & 6,59 & $6^{\mathrm{bB}}$ & 40,66 & $37^{\mathrm{A}}$ & 61,54 & $56^{\mathrm{B}}$ & 48,36 & $44^{\mathrm{A}}$ & 31,87 & $29^{\mathrm{B}}$ \\
\hline
\end{tabular}

$\mathrm{J} 5 \mathrm{~V}=$ vacas vacinadas; $\mathrm{J} 5$ Vcont $=$ vacas controle $;{ }^{1} \mathrm{SEC}=$ Secagem, ${ }^{2}$ POS = Pós-parto; ${ }^{\mathrm{a}, \mathrm{b}}$ Frequên cias seguidas de letras minúsculas distintas, na mesma coluna, indicam diferenças estatísticas, entre grupos, pelo Teste Exato de Fisher $(\mathrm{p} \leq 0,05)$; ${ }^{\mathrm{A}, \mathrm{B}}$ Frequências seguidas de letras maiúsculas distintas, na mesma linha, indicam diferenças estatísticas significativas entre secagem e pós-parto, no mesmo grupo e para o mesmo microrganismo, pelo Teste de McNemar $(\mathrm{p}<0,05)$; * Nesta categoria estão incluídos os patógenos Bacillus sp., Streptococcus sp., Pseudomonas sp. e Leveduras. 
por coliformes, visto que a proteção oferecida pela vacinação com E. coli J5 é atribuída ao aumento na concentração de anticorpos que possuem reação cruzada contra várias espécies de bactérias Gram-negativo (Hogan et al. 1992c).

Apesar da terapia de vacas secas não apresentar eficiência comprovada contra bactérias Gram-negativas, esta é capaz de aumentar a taxa de cura em animais infectados por outros tipos de patógenos e prevenir a ocorrência de novas infecções durante o período seco (Bradley \& Green 2001). Este fato torna-se evidente quando se observam os resultados do presente estudo em que, ambos os grupos, os quais foram tratados com antibióticos específicos para vacas secas no dia da secagem, apresentaram redução na prevalência de infecções causadas por outros tipos de microrganismos, de $54,17 \%$ na secagem para $25,00 \%$ no pós-parto em vacas vacinadas e de $40,45 \%$ na secagem para $31,87 \%$ no pós-parto em vacas não vacinadas.

Durante o período seco, em especial após o período de involução completa da glândula mamária, esta é parcialmente resistente às infecções devido aos altos níveis de lactoferrina presentes na secreção mamária (Bradley e Green 2004). Esta proteína possui capacidade bacteriostática, principalmente, por tornar os níveis de ferro na glândula mamária indisponíveis (Green et al. 2002, Kutila et al. 2003, Chaneton et al. 2008). Estudos realizados por Diarra et al. (2002) indicam, ainda, uma potente atividade bactericida da lactoferrina por meio do aumento da permeabilidade da membrana celular bacteriana e lesão da parede celular externa, particularmente, em bactérias Gram-negativo, podendo aumentar o efeito de alguns antimicrobianos. Este fato pode justificar os resultados aqui apresentados, nos quais nota-se a ocorrência de diminuição na porcentagem de vacas infectadas no grupo de vacas não vacinadas (J5Vcont), ainda que menos acentuada quando comparadas às vacinadas $(\mathrm{J} 5 \mathrm{~V})$, podendo-se atribuí-la ao aumento na taxa de cura espontânea dos animais, presente no período seco pela ação da lactoferrina, bem como outros fatores imunológicos inerentes ao animal nesta fase fisiológica (Burvenich et al. 2007), associada à terapia de vacas secas. Assim, verifica-se que o período seco é ideal para se conseguir uma completa sinergia entre a terapia antimicrobiana e a função imune para eliminação de patógenos da glândula mamária, sem incorrer nos elevados custos típicos das terapias para vacas em lactação.

A ação da lactoferrina nas secreções mamárias é ainda maior contra bactérias Gram-negativo, em especial, E.coli, como demonstrado por Chaneton et al. (2008) que observaram que a inibição do crescimento E.coli depende das concentrações de lactoferrina na glândula mamária. Ainda, Todhunter et al (1990) verificaram que esta inibição pode ser otimizada pela presença de imunoglobulinas, uma vez que a combinação imunoglobulina e lactoferrina resultou em significativas reduções no crescimento de E. coli, comparadas a ação isolada da lactoferrina, indicando que os anticorpos presentes na secreção mamária que interagem com a lactoferrina são mais efetivos contra E. coli. Assim, de acordo com os achados aqui expostos e baseados nos estudos de Chaneton et al. (2008) e Todhunter et al. (1990), a redução observada, na prevalência de infecções intrama- márias no pós-parto, resulta da associação entre as altas concentrações de lactoferrina e imunoglobulinas na glândula mamária durante o período seco, juntamente com sua capacidade bacteriostática, bem como sua capacidade em aumentar a eficiência do antibiótico de vacas secas. A interação entre estes fatores pode levar a um aumento na taxa de cura dos animais, limitando o estabelecimento de IMM neste período.

Devido ao fato de vacas vacinadas (J5V) terem apresentado redução mais pronunciada na prevalência de E. coli no pós-parto, comparadas às não vacinadas (J5Vcont) e, ainda, de a lactoferrina apresentar otimização do potencial de ação quando associada às imunoglobulinas (Todhunter et al. 1990), verifica-se que a vacinação com $E$. coli J5 pode ter influenciado na redução da prevalência de $E$. coli no pós-parto, potencializando a ação da lactoferrina e aumentando a taxa de cura espontânea. Esta potencialização se deve ao aumento nos níveis de anticorpos no colostro e nas secreções mamárias que reconhecem E. coli, devido a vacinação com E. coli J5, diminuindo a suscetibilidade dos animais em adquirir o agente no período pré-parto, como proposto por Tomita et al. (2000).

Apesar de não terem sido avaliados os títulos de imunoglobulina no presente estudo, pesquisas anteriores demonstraram que vacas vacinadas com E. coli J5 apresentaram títulos de IgM e IgG, nas secreções mamárias, maiores do que vacas não vacinadas, estando os mesmos relacionados ao aumento da capacidade fagocítica e opsonizadora para leucócitos e macrófagos. Este aumento está envolvido na prevenção da colonização da glândula mamária pelos organismos invasores e aumento da taxa de eliminação destes quando a infecção já se encontra estabelecida (Gonzáles et al. 1989, Hogan et al. 1992). Assim, pelos resultados observados neste estudo, pode-se admitir a possibilidade de que o aumento nos títulos de anticorpos, em vacas vacinadas com E. coli J5, seja capaz de induzir uma proteção inicial, em vacas, antes do início do período de alto risco de aquisição de IMM, isto é, o período pré-parto.

Todavia, o presente estudo contrasta com resultados obtidos em estudos anteriores, os quais não encontraram redução na prevalência de IIM causadas por E. coli e pelo uso da imunização com E. coli J5 (Hogan et al. 1992b, 1992c, 1995, 1999, Clark \& Van Rockel 1994, Tomita et al. 1998, Smith et al. 1999). As discrepâncias observadas entre este estudo e estudos anteriores são atribuídas, principalmente, às diferenças metodológicas entre os mesmos. A maioria destes estudos utilizou infecção experimental, isto é, inoculação intramamária de E. coli para avaliação da resposta animal, e não a avaliação da resposta baseada na infecção natural por este agente, como aqui apresentado.

Os achados deste estudo estão de pleno acordo com estudos prévios que avaliaram a eficiência da vacinação com E. coli J5 na prevenção da ocorrência de IMM por E. coli no pós-parto, naturalmente adquiridas, em rebanhos comerciais e com a administração de três doses da vacina (González et al. 1989, 1996, Cullor 1991, Hogan et al. 1992b). Em concordância ao presente estudo, os anteriores demonstraram a redução na prevalência de infecções causadas por $E$. coli no pós-parto em vacas vacinadas com E. coli J5. 
No Quadro 2 apresenta-se a ocorrência de IMM por $E$. coli que se tornaram clínicas no pós-parto em vacas vacinadas e não vacinadas. No grupo de vacas vacinadas (J5V) não houve manifestação do caso clínico no único animal positivo para E. coli no pós-parto. A diferença entre os grupos foi estatisticamente significativa $(p<0,05)$. Os resultados evidenciam a eficiência da vacina $E$. coli J5 na prevenção da ocorrência de casos clínicos de mastite no início da lactação, mesmo quando o animal já se encontra infectado por $E$. coli no pós-parto. Esta prevenção pode ser justificada com base nos achados de Hogan et al. (1992a, 1995), os quais verificaram que $66,7 \%$ das IMM no pós-parto em vacas não vacinadas se tornaram clínicas nos primeiros 90 dias de lactação, comparadas a $20 \%$ em vacas vacinadas com $E$. coli J5. Os autores demonstraram que a imunização com $E$. coli J5 pode aumentar a capacidade de defesa do animal à infecção, por meio do estímulo da produção de anticorpos específicos contra antígenos de núcleo do LPS, os quais são comuns a todas as bactérias Gram-negativas, promovendo a eliminação do patógeno sem a apresentação de sinais clínicos (Burvenich et al. 2007). Ainda, Smith et al. (1999), utilizando a mesma metodologia empregada no presente estudo, observaram que, durante os primeiros 90 dias de lactação, as vacas vacinadas apresentaram risco cinco vezes menor de apresentação de mastite clínica por coliformes, quando comparadas as não vacinadas.

\section{Quadro 2. Infecções Intramamárias (IMM) por Escherichia coli que se tornaram clínicas no pós-parto, em vacas vacinadas e não vacinadas}

\begin{tabular}{lcccccc}
\hline \multirow{2}{*}{ Grupos } & \multicolumn{2}{c}{$\begin{array}{c}\text { Prevalência } E \text {.coli } \\
\text { no pós-parto }\end{array}$} & & \multicolumn{2}{c}{$\begin{array}{c}\text { IIM por E. coli que } \\
\text { se tornaram clínicas }\end{array}$} \\
\cline { 2 - 3 } \cline { 5 - 7 } & $\mathrm{n}$ & $\%$ & & $\mathrm{n}$ & $\%$ \\
\hline J5V (n=96) & 1 & 1 & & $0^{\text {a }}$ & 0 \\
J5Vcont (n=91) & 6 & 6,5 & & $4^{\mathrm{b}}$ & 66,6
\end{tabular}

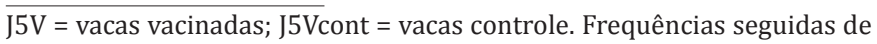
letras minúsculas distintas diferem estatisticamente pelo Teste de McNemar $(\mathrm{p}<0,05)$.

No Quadro 3 apresenta-se o total de casos clínicos de mastite nos primeiros 100 dias de lactação em vacas, vacinadas e não vacinadas. Quando comparados o grupo vacinado e não vacinado, considerando-se a ocorrência de casos clínicos totais, isto é, os resultados combinados de casos clínicos causados tanto por E. coli quanto negativos na cultura microbiológica, observa-se que o grupo de vacas não vacinadas (J5Vcont) apresentou maior número $(p<0,05)$ de casos clínicos totais. Contudo, quando estratificados os dados da cultura microbiológica, ou seja, os casos clínicos causados por E. coli e negativos, isoladamente, não houve diferença estatística entre os grupos. As quantidades de unidades formadoras de colônia (UFC) no leite, para bactérias Gram-negativas, são, muitas vezes, menores que $100 \mathrm{UFC} / \mathrm{ml}$ durante o caso clínico ou subclínico da doença, dificultando seu isolamento em determinadas circunstâncias. Conforme o exposto, os casos negativos na cultura microbiológica foram aqui considerados, uma vez que animais que apresentam casos clínicos de mastite, com resultado negativo na cultura microbiológica, podem estar
Quadro 3. Total de vacas que apresentaram casos clínicos de mastite nos primeiros 100 dias de lactação

\begin{tabular}{|c|c|c|c|c|c|c|}
\hline \multirow[t]{2}{*}{ Grupo } & \multicolumn{2}{|c|}{ Escherichia coli } & \multicolumn{2}{|c|}{ Negativo } & \multicolumn{2}{|c|}{ Total } \\
\hline & $\mathrm{n}$ & $\%$ & $\mathrm{n}$ & $\%$ & $\mathrm{n}$ & $\%$ \\
\hline $\mathrm{J} 5 \mathrm{~V}(\mathrm{n}=96)$ & 11 & 11,45 & 9 & 9,37 & 20 & $20,83^{a}$ \\
\hline J5Vcont $(n=91)$ & 19 & 20,87 & 14 & 15,38 & 33 & $36,26^{b}$ \\
\hline
\end{tabular}

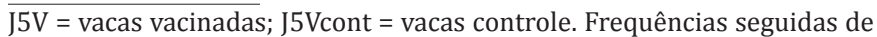
letras minúsculas distintas diferem estatisticamente pelo Teste Exato de Fisher $(\mathrm{p}<0,05)$.

infectados por E. coli, pelo fato da bactéria poder se encontrar metabolicamente inativa na amostra coletada, dificultando a identificação do agente (Hogan \& Smith 2003).

Muitas das IMM, por bactérias Gram-negativas, adquiridas no fim do período seco, podem se manifestar como casos clínicos de mastite no início da lactação, devido ao comprometimento imunológico associado ao pós-parto (Bradley \& Green 2000, Burvenich et al. 2007). Os resultados do presente estudo demonstram que a imunização de vacas, com E. coli J5 pode influenciar na redução da ocorrência de casos clínicos de mastite, tanto no momento pós-parto imediato, quanto nos primeiros 100 dias de lactação. Estes achados condizem com o proposto por Tomita et al. (2000), que relataram que o mecanismo de ação da vacinação com E. coli J5, contra as mastites clínicas causadas por E. coli, consiste na proteção por meio do aumento da opsonização do LPS bacteriano e aumento dos títulos de anticorpos séricos e no leite. Em um estudo de campo, altos títulos de IgG $\mathrm{I}_{1}$ no soro, contra E. coli J5, foram associados com diminuiçã̃o na incidência de mastites clínicas por coliformes (Tyler et al. 1988). Este aumento na opsonização do LPS bacteriano promove uma maior migração de polimorfonucleares (PMN) para o interior da glândula mamária, além de aumentar a capacidade fagocítica dos mesmos, gerando maior eliminação de bactérias do interior da glândula e diminuindo a incidência de casos clínicos de mastite (Tomita et al. 2000, Burton \& Erskine 2003, Burvenich et al. 2007).

No Quadro 4 apresenta-se a intensidade dos casos clínicos de mastite, causados por E.coli, em vacas, vacinadas e não vacinadas, ocorridos durante o período experimental. Verifica-se que apenas o grupo de vacas não vacinadas (J5Vcont) apresentou casos clínicos de grau 3 - casos severos com sinais sistêmicos. Em 7\% (2/33) dos casos clínicos de mastite neste grupo, houve manifestação de sinais sistêmicos, comparados a nenhum animal do grupo vacinado. No entanto, não foram observadas diferenças estatísticas $(p>0,05)$ com relação à intensidade (graus) dos casos clínicos entre os grupos vacinados (J5V) e não vaci-

Quadro 4. Intensidade dos casos clínicos de mastite, causados por Escherichia coli durante todo o período experimental

\begin{tabular}{|c|c|c|c|c|c|c|}
\hline \multirow[t]{2}{*}{ Grupo } & \multicolumn{2}{|c|}{ Grau 1} & \multicolumn{2}{|c|}{ Grau 2} & \multicolumn{2}{|c|}{ Grau 3} \\
\hline & $\mathrm{n}$ & $\%$ & $\mathrm{n}$ & $\%$ & $\mathrm{n}$ & $\%$ \\
\hline$J 5 V(n=20)$ & 15 & 75 & 5 & 25 & 0 & 0 \\
\hline J5V cont $(n=33)$ & 22 & 66 & 9 & 27 & 2 & 7 \\
\hline
\end{tabular}

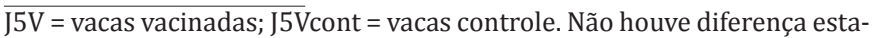
tística significativa entre os grupos pelo Teste Exato de Fisher $(\mathrm{p}>0,05)$. 
nados (J5Vcont). Porém, uma análise descritiva dos dados faz-se interessante devido à ausência de casos severos em animais vacinados. É importante enfatizar que se trata de um estudo a campo, observando-se as infecções naturais pelo agente diferindo, portanto, de resultados obtidos em estudos com infecções experimentais, mas que estão de pleno acordo com estudos anteriores (González et al. 1989, Hogan et al. 1994, 1995, Tomita et al. 2000). Estes reportam que mais de $90 \%$ das IMM experimentais levam ao desenvolvimento de casos clínicos agudos de mastite por $E$. coli, tanto em animais vacinados quanto em não vacinados, comparados a menos de 10\% nas ocorrências naturais. Assim, embasado nestes estudos e pelos resultados aqui apresentados, sugere-se que a imunização com E. coli J5 pode ser eficaz em reduzir a intensidade dos sinais clínicos de mastite causados por E. coli. Entretanto, estudos mais detalhados com a observação de maior número de casos clínicos são necessários.

0 mecanismo pelo qual a vacinação com $E$. coli J5 atua, reduzindo a incidência e intensidade dos casos clínicos, ainda não é totalmente conhecido. Contudo, realizando a análise descritiva dos dados, os resultados aqui apresentados podem ser justificados, baseando-se em uma das hipóteses da eficácia da imunização com E. coli J5, em que a proteção oferecida pela vacinação, aparentemente, está relacionada ao aumento na produção de anticorpos específicos contra antígenos do núcleo do LPS e aumento na opsonização de bactérias (Dosgne et al. 2002, Hogan \& Smith. 2003). 0 pico de contagem bacteriana e a intensidade dos sinais clínicos da doença são dependentes da rapidez e eficiência da resposta dos neutrófilos e da opsonização de bactérias pelos anticorpos (IgG e IgM), facilitando, assim, o reconhecimento destas para a fagocitose e, conseqüentemente, morte intracelular (Hogan et al. 1995, Tomita et al. 2000, Hogan \& Smith 2003, Burvenich et al. 2007, Wilson et al. 2007). Assim, observa-se uma redução no número de bactérias no interior da glândula mamária, com subsequente redução na intensidade dos casos clínicos. No presente estudo, nota-se que apenas as vacas não-vacinadas (J5Vcont) apresentaram casos clínicos de mastite com manifestação sistêmica, demonstrando que a vacinação com $E$. coli J5, em vacas, pode promover uma eliminação eficiente da bactéria e neutralização do LPS, responsável pelos sinais sistêmicos dos casos clínicos de mastite causados por E. coli.

Outro fator que corrobora a hipótese aqui apresentada são os achados de Shafer-Weaver et al. (1999) e Wilson et al. (2007), os quais demonstraram que os títulos séricos de IgG $_{1}$ e IgG Ig $_{2}$ contra E. coli J5 são significativamente maiores em vacas vacinadas, comparadas as não vacinadas. Este fato, em especial o aumento dos títulos de $\operatorname{IgG}_{2}$, favorece a formação da resposta imunológica do tipo 1 , importante contra a mastite bovina, principalmente no início da infecção, uma vez que esta imunoglobulina auxilia na fagocitose da bactéria pelo neutrófilo pela rápida fixação do complemento (Burton \& Erskine 2003). Sabendo-se que a resposta imunológica em vacas no início da lactação é predominantemente do tipo 2, esta mudança do tipo de resposta, com predominância da $\operatorname{IgG}_{2}$, é extremamente benéfica na redução dos sinais clínicos. A viabilidade de maiores títulos de $\mathrm{IgG}_{2}$ contra E. coli J5, imediatamente após a invasão bacteriana da glândula mamária, parece ser um dos maiores benefícios da vacinação com E. coli J5, principalmente se verificarmos que as concentrações desta imunoglobulina em vacas não vacinadas ocorre 12 horas após a invasão de $E$. coli, enquanto em vacas vacinadas este aumento ocorre em, aproximadamente, quatro horas (Shafer-Weaver et al. 1999). Portanto, estes achados explicam o fato de casos clínicos de mastite com sinais agudos terem ocorrido apenas em animais não vacinados, como apresentado neste estudo.

No entanto, mesmo com a utilização da vacina $E$. coli J5, observa-se que alguns animais vacinados apresentaram casos clínicos de mastite de grau 2 (Quadro 4), caracterizados pela presença de coágulos e sinais de inflamação no úbere com edema e aumento de temperatura. No grupo de vacas vacinadas (J5V), 25\% dos animais apresentaram caso clínico de grau 2. Este fato é elucidado baseado em Dosgne et al (2002) que propuseram que há diferenças individuais entre os animais no que se refere a resposta à imunização com E. coli J5, podendo-se classificá-los em animais com alta ou baixa resposta à imunização baseado na magnitude da resposta de anticorpos contra E. coli J5. Aproximadamente um terço das vacas responde normalmente à imunização, enquanto dois terços dos animais demonstram um grau variável de resposta á imunização no periparto. Estes achados indicam que, neste período, há enfraquecimento da resposta de anticorpos a imunização ativa, havendo, portanto, aumento da suscetibilidade destes animais de baixa resposta a novas infecções, por $E$. coli, no período pré-parto. Portanto, apesar da imunização com E. coli J5 ser eficaz em auxiliar na redução da intensidade dos sinais clínicos de mastite, como aqui apresentado, espera-se que, em rebanhos submetidos a altos desafios ambientais, casos de mastite moderados (grau 2) ou severos (grau 3) ocorram, mesmo após as imunizações.

O Quadro 5 apresenta as médias das CCS e produção de leite em vacas vacinadas e não vacinadas, nos primeiros 100 dias de lactação. Não foram observadas diferenças significativas $(p>0,05)$ com relação à CCS nos animais vacinados (J5V) e não vacinados (J5Vcont). É relevante considerar que a maioria das IMM causadas por coliformes, em especial Escherichia coli, são caracterizadas por serem de curta duração e frequentemente com manifestação clínica aguda. No presente estudo foram realizadas apenas três avaliações da CCS dos animais, intercaladas de um mês, estas podem não ter sido suficientes para se avaliar o efeito da vacina

Quadro 5. Média da contagem de células somáticas (CCS) ( $\log 10$ células/mL) do leite e produção de leite (kg de leite/ vaca/dia) de vacas vacinadas e não vacinadas nos primeiros 100 dias de lactação

\begin{tabular}{llllll}
\hline \multirow{2}{*}{ Grupo } & \multicolumn{2}{c}{ Variáveis } & & \multicolumn{2}{c}{ (Médias $\pm \mathrm{s}$ ) } \\
\cline { 2 - 2 } \cline { 5 - 6 } & \multicolumn{2}{c}{$\begin{array}{c}\text { CCS } \\
\text { (células } / \mathrm{mL})\end{array}$} & & $\begin{array}{c}\text { Produção } \\
\text { (kg leite/vaca/dia) }\end{array}$ \\
\hline J5V (n=96) & $4,75^{\text {a }}$ & $\pm 0,63$ & & $22,79^{\text {a }}$ & $\pm 7,09$ \\
J5Vcont $(n=91)$ & $4,80^{\text {a }}$ & $\pm 0,68$ & & $21,26^{\text {b }}$ & $\pm 6,04$
\end{tabular}

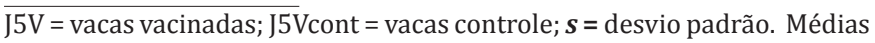
seguidas de letras distintas, nas colunas, diferem estatisticamente pelo Teste SNK $(\mathrm{p}<0,05)$. 
E. coli J5 na redução da CCS, principalmente, após a manifestação do caso clínico de mastite. Entretanto, estudos anteriores demonstraram o efeito protetor da vacina por meio da observação dos valores de CCS do leite de vacas vacinadas com $E$. coli $\mathrm{J} 5$, após desafio intramamário com E. coli, em média de 500.000 células/mL contra 5.000 .000 células/mL para vacas controle. Além disso, 30 horas após o desafio, as vacas vacinadas apresentaram redução na CCS para 300.000 células $/ \mathrm{mL}$, enquanto as controle apresentaram média de 2.000 .000 células $/ \mathrm{mL}$. Esta redução na CCS é um importante indicador da menor reação inflamatória na glândula mamária de vacas vacinadas, demonstrando menor intensidade dos sinais clínicos associada aos efeitos da imunização com E. coli J5 (Wilson et al. 2007).

Com relação à produção de leite, observou-se que as não vacinadas (J5Vcont) apresentaram média de produção de leite inferior $(\mathrm{p}<0,05)$ às vacas do grupo vacinado $(\mathrm{JV})$ nos primeiros 100 dias de lactação (Quadro 5). Neste período, a média de produção de vacas não vacinadas (J5Vcont) foi de $21,26 \mathrm{~kg}$ de leite/vaca/dia, enquanto as vacinadas (J5V) apresentaram média de produção $22,79 \mathrm{~kg}$ de leite/ vaca/dia, ou seja, o grupo não vacinado produziu $1,53 \mathrm{~kg}$ de leite/vaca/dia a menos comparado ao grupo vacinado. Um estudo realizado por Wilson et al. (2008) relatou que a vacinação com E.coli $\mathrm{J} 5$ esteve associada à menor redução na produção de leite, após casos clínicos de mastite, em vacas vacinadas comparada às controles. Vacas vacinadas apresentaram uma produção diária de leite de 7 a $16 \mathrm{~kg}$ maior que vacas não vacinadas cerca de três semanas após a manifestação do caso clínico de mastite, com início nos primeiros 50 dias de lactação, e aproximadamente $2 \mathrm{~kg}$ de leite a mais durante toda a lactação. Estes achados estão de acordo com os aqui expostos, nos quais, a imunização com E. coli $\mathrm{J} 5$ esteve associada à maior produção de leite nos três primeiros meses de lactação.

Os resultados aqui apresentados, em conjunto com os achados de Wilson et al. $(2007,2008)$, indicam que a imunização com E. coli J5 está relacionada ao retorno mais rápido da produção de leite após o caso clínico, uma vez que ocorre redução na intensidade dos sinais clínicos, permitindo o restabelecimento das funções de produção da glândula mamária, com menores efeitos deletérios na produção de leite durante a lactação.

\section{CONCLUSÕES}

A vacinação com Escherichia coli J5 demonstrou-se eficaz em reduzir a prevalência de infecções intramamárias no pós-parto, bem como a ocorrência e intensidade dos casos clínicos de mastite, causados por E. coli, nos primeiros 100 dias de lactação.

A contagem de células somáticas não é alterada pela utilização da vacina $E$. coli $\mathrm{J} 5$ e vacas imunizadas com $E$. coli J5 produzem mais leite nos primeiros 100 dias de lactação.

\section{REFERÊNCIAS}

Bradley A.J. \& Green M.J. 2000. A study of the incidence and significance of intramammary enterobacteriacel infections acquired during the dry period. J. Dairy Sci. 83:1957-1965.
Bradley A.J. \& Green M.J. 2001. An investigation of the impact of intrammary antibiotic dry cow therapy on clinical mastitis. J. Dairy Sci. 84:16321639.

Bradley A.J. \& Green M.J. 2004. The importance of nonlactating period in the epidemiology of intrammamary infection and strategies for prevention. Vet. Clin. Food. Anim. 20:547-568.

Brito M.A.V.P. \& Brito J.R.F. 1999. Diagnóstico microbiológico da mastite. Embrapa Gado de Leite, Juiz de Fora, 55:26.

Burton J.L. \& Erskine R.J. 2003. Immunity and mastitis some new ideas for an old disease. Vet. Clin. North Am. Food Anim. Pract. 19:1-45.

Burvenich C., Bannerman J.D. \& Lippolis D.J. 2007. Cumulative physiological infections during the transition period. J. Dairy Sci. 90:39-54.

Chaneton L., Tirante L. \& Maito J. 2008. Relationship between milk lactoferrin and etiological agent in the mastitic bovine mammary gland. J. Dairy Sci. 91:1865-1873.

Clark P. \& Van Roeke L.D. 1994. Efficacy of an Escherichia coli Bacterin for the control of coliform mastitis in dairy cows. Agri-practice. 15:19-25.

Cullor J.S. 1991. The Escherichia coli J5 vaccine: investigating a new tool to combat mastitis. Vet. Med. 86:836-844.

Diarra M.S., Petitclerc D. \& Lacasse P. 2002. Effect of lactoferrin in combination with penicillin on the morphology and physiology of Staphylococcus aureus isolated from bovine mastitis. J. Dairy. 85:1141-1149.

Dosogne H., Vangroenweghe F. \& Burvenich C. 2002. Potencial mechanism of action of $\mathrm{J} 5$ vaccine in protection against severe bovine coliform mastitis. Vet. Res. 33:1-12.

González R.N., Wilson D.J., Mohammed H.N., Sears P.M., Rivas A.L. \& Campbell S.G. 1996. A placebo-controlled trial of an Escherichia coli J5 bacterin and ribotyping-based assessment of coliform bacteria diversity on a dairy farm. Anais 19 Congresso Mundial de Buiatria, Edimburgo, UK, p.277-280.

González R.J., Cullor J.S. \& Jasper D. 1989. Prevention of clinical coliform mastitis in dairy cows by a mutant Escherichia coli vaccine. Can. J. Vet. Res. 53:301-305.

Green M.J., Green L.E. \& Medley G.F. 2002. Influence of dry period bacterial intramammary infection on clinical mastitis in dairy cows. J. Dairy Sci. 85:2589-2599.

Harmon R.J., Eberhart R.J., Jasper D.E., Langlois B.E. \& Wilson R.A. 1990. Microbiological procedures for the diagnosis of bovine udder infection. NMC. 34p.

Hogan J. \& Smith K.L. 2003. Coliform mastitis. Vet. Res. 34:507-519.

Hogan J.S., Bogacz V.L. \& Aslam M. 1999. Efficacy of an Escherichia coli J5 bacterin administered to primigravid heifers. J. Dairy Sci. 82:939-943.

Hogan J.S., Smith K.L., Hoblet K.H., Schoenberger P.S., Todhunter D.A., Hueston W.D., Pritchard D.E., Bowman G.L., Heider L.E. \& Brockett B.L. 1992a. Field survey of clinical mastitis in low somatic cell count herds. J. Dairy Sci. 72:1547-1556.

Hogan J.S., Weiss W.P., Todhunter D.A., Smith K.L. \& Schoenberger P.S. 1992b. Efficacy of an Escherichia coli J5 Mastitis Vaccine in an Experimental Challenge Trial. J. Dairy Sci. 75:415-422.

Hogan J.S., Todhunter D.A., Tomita G.M., Smith K.L. \& Schoenberger P.S. 1992c. Opsonic activity of bovine serum and mammary secretion after Escheria coli J5 vaccination. J. Dairy. Sci. 75:72-77.

Hogan J.S., Weiss W.P. \& Smith K.L. 1994. Role of vitamin E and selenium in host defense against mastitis. J. Dairy Sci. 76:2795-2803.

Hogan J.S., Weiss W.P. \& Smith K.L. 1995. Effects of an Escherichia coli J5 vaccine on mild coliform mastitis. J. Dairy Sci. 78:285-290.

Kutila T., Pyörälä S. \& Saloniemi H. 2003. Antibacterial effect of bovine lactoferrin against udder pathogens. Acta Vet. Scand. 44:35-42.

NMC 1999. Laboratory Handbook on Bovine Mastitis. National Mastitis Council, Madison, WI, p.171-173.

SAS Institute 1999. SAS User's Guide: statistics version $8^{\text {th }}$ ed. SAS Inst., Cary, NC.

Shafer-Weaver K.A., Corl C.M. \& Sordillo L.M. 1999. Shifts in bovine CD4+ 
subpopulations increase T-helper-2 compared with T-helper-1 effector cells during the postpartum period. J. Dairy Sci. 82:1696-1706.

Smith J.L., Hogan J.S. \& Smith K.L. 1999. Efficacy of intramammary immunization with Escherichia coli J5 bacterin. J. Dairy. Sci. 82:2582-2588.

Todhunter D.A., Smith K.L. \& Hogan, J.S. 1990. Growth of gram-negative bacteria in dry cow secretion. J. Dairy. Sci. 73:363-372.

Tomita G.M., Nickerson S.C., Owens W.E. \& Wren B. 1998. Influence of route of Vaccine administration against experimental intramammary infection caused by Escherichia coli. J. Dairy Sci. 81:2159-2164.

Tomita G.M., Ray C.H. \& Nickerson S.C. 2000. A comparison of two commercially available Escherichia coli $\mathrm{J} 5$ vaccines against $E$. coli intramammary challenge. J. Dairy Sci. 83:2276-2281.
Tyler J.W., Cullor J.S., Osburn B.L., Bushnell R.B. \& Fenwick B.W. 1988. Relationship between serological recognition of Escherichia coli 0111: B4 (J5) and clinical coliform mastitis in cattle. Am. J. Vet. Res. 49:19501954.

Wilson D.J., Grohn Y.T., Bennett G.J., González R.N., Schukken Y.H. \& Spatz J. 2008. Milk production change following clinical mastitis and reproductive performance compared among J5 vaccinated and control dairy cattle. J. Dairy Sci. 91:3869-3879.

Wilson D.J., Mallard B.A., Burton J.L., Schukken Y.H. \& Gröhn Y.T. 2007. Milk and serum J5-specific antibody responses, milk production change, and clinical effects following intramammary Escherichia coli challenge for J5 vaccine and control cows. Clin. Vaccin. Immunol. 14:693699. 